\title{
A Century of Reading Time: From Modernist Novels to Contemporary Comics
}

\author{
Aimee Armande Wilson
}

Finding new ways to depict time propelled many of the experiments with literary form that characterize modernism. Frequently, these experiments were aimed at portraying the tension between time as represented on a clock and time as experienced in the human psyche. To achieve this end, drastic changes to the form of the novel were necessary because its basic organizational pattern is linear, characterized by a constant push forward that is similar to the clock's inevitable march into the future. ${ }^{1}$ Experiential time as experienced in the human psyche, however, is full of stops, starts, reversals, and leaps forward. Time seems to speed up when we are enjoying ourselves, and trips to the dentist make the minutes crawl by; experiential time is anything but evenly meted out like the hour marks on a clock face. Gertrude Stein's continuous present, Marcel Proust's involuntary memory, and James Joyce's use of repetition are some of the bestknown examples of modernist attempts to disrupt the novel's linear progression into the future.

In contrast to the novel's linear orientation, paintings are often understood to be oriented radially, or in a manner that presents the entire work simultaneously. ${ }^{2}$ In other words, radial orientation causes the viewer to contemplate that which is above, below, or beside, rather than only what comes before and after. It is a critical commonplace to argue that modernist literature attempted to break down this division between linear and radial orientation by adapting painting techniques for literature. What is not frequently observed is the way in which comics, too, 
combine the linear organization of novels with the radial orientation of images (significantly, the genre of comics as we know it came into being in the late nineteenth and early twentieth centuries $^{3}$ ). In “Time and Free Will: Bergson, Modernism, Superheroes, and Watchmen," Eric Berlatsky argues that the genre of comics "is both a 'time-art' in the manner of literature (as one must spend time sequentially reading word by word and panel by panel), and a 'space-art' capable of being viewed in a single moment."4 Berlatsky's essay analyzes the similarities between comics and canonical modernist literature as regards Henri Bergson's notions of space and time. I have no interest in recapitulating or critiquing Berlatsky's perceptive argument, but rather seek to build on the idea that comics are a spatial and temporal medium from a readerresponse perspective.

Although comics retain much of the linear orientation of novels - with the storyline driving the reader forward - the radial orientation of each panel invites the reader to linger in the image until his or her curiosity is satisfied and take in the various parts of the image in whichever order he or she chooses. This orientation is reflective of and conducive to the reversals, gaps, and pauses that characterize psychological time. In this way, then, comics replicate - and even amplify - in the reading experience the tension between clock time and psychological time that so often appears in modernist works. The linear-radial orientation of comics can therefore be read as an addition to the panoply of modernist techniques that interrupt the linear progression of clock time with time as felt by the individual.

Of course, not all comics are self-aware of the tension caused by this linear-radial orientation. The League of Extraordinary Gentlemen (1999-present), by Alan Moore and Kevin O’Neill, is an exception and therefore a particularly illustrative case study because it plays with the difference between clock and psychological time in both form and content. The series is, in 
Thomas Mann's terms, a "tale of time" - one operating on the basis of time passing (which all tales are) - as well as a "tale about time," one dealing directly with time and its impact on characters. ${ }^{5}$ Of particular interest to my argument is the third volume in Moore and O'Neill's series, titled Century. The volume is divided into three chapters: "1910," "1969," and "2009" (note that the titles themselves draw our attention to clock time). League brings together fictional characters in a deliberate pastiche of time periods, genres, and nationalities. Characters include Orlando, the gender-bending protagonist from Virginia Woolf's Orlando: A Biography (1928), and Mina Murray, a reprisal of Bram Stoker's character from Dracula (1897), as well as the Invisible Man, Dr. Jekyll/Mr. Hyde, Allan Quatermain, and James Bond, to name just a few. These characters form a vigilante group engaged in combating threats to the British Empire. Although most characters stem from Victorian texts, the series nevertheless draws characters from an array of time periods, both in terms of the periods in which the characters' narratives are set and the publication dates of the books in which they star. Adding to this temporal dislocation, many of the characters in League are immortal. As this fact should make clear, Moore's depictions of these famous personages are not always faithful to the original, but the connections are unmistakable. For example, Orlando is referred to as "the new Vita" in Century: 1969, an allusion to Vita Sackville-West, the person on whom Woolf's Orlando is based. ${ }^{6}$ In terms of form, League is similar to other comics in that it engages the tension between clock and psychological time by virtue of its linear-radial orientation. In terms of content, the series is distinct from most comics in that it engages a modernist conception of time, most directly through the character of Orlando. I will address the linear-radial orientation of comics before discussing the ways in which clock time is personified in League's Orlando; doing so 
encourages us to see the ways in which clock time - usually thought to be an objective, public dimension of time - is actually quite subjective.

\section{Versions of Time}

William Faulkner famously said, "the past is never dead. It's not even past,"7 and his works manifest this sentiment via myriad techniques that fold the past into the future. Faulkner was not alone in his focus on time, of course. As Randall Stevenson states,

Modernist writing generally ... gave up, amended or abbreviated the chronological sequence, the vision of life as a series, which had conventionally structured the novel in the nineteenth century. The progressive, sequential development of the Bildungsroman, for example - tracing its central figure's life, step by step, over many years from birth to maturity - is at a considerable remove from the work of Joyce or Woolf, following their protagonists through only single days in Ulysses (1922) or Mrs. Dalloway (1925). ${ }^{8}$

This sequential progress of the novel was difficult to interrupt because, as noted earlier, the organizational paradigm of the novel is linear, a "sequential design mirror[ing] a temporal order" that progresses persistently forward. ${ }^{9}$

Modernists attempted in many ways to interrupt the linear organization of the novel: to make readers feel as though time had slowed down or gone in reverse; to, in effect, make the reading experience of a novel more like time as experienced in a character's psyche. The most obvious technique used to achieve this end is the simple addition of words to amplify the importance and richness of a character's thoughts. Virginia Woolf, for example, takes some four pages to describe Mrs. Ramsay's stream-of-consciousness while she measures the length of a 
knitted sock against her son's leg in To the Lighthouse (1927). As Erich Auerbach states of this scene and others similar to it, "the road taken by consciousness is sometimes traversed far more quickly than language is able to render it." ${ }^{\prime 10} \mathrm{~A}$ second technique used by writers to interrupt clock time is defamiliarization, to use Viktor Shklovsky's term. He writes, "The technique of art is to make objects 'unfamiliar,' to make forms difficult, to increase the difficulty and length of perception because the process of perception is an aesthetic end in itself and must be prolonged." 11 This method forces readers to slow down to orient themselves to the world of the novel (as in the Benjy section of The Sound and the Fury). The forward pull of the linear narrative is slowed by the reader's desire for comprehension. A third favored method is repetition to create a sort of circularity, to fold the past of the novel into the present and the future; Molly Bloom's yeses in the final chapter of Ulysses are an obvious example.

Many of these formal experiments with time were, of course, directly inspired by the theories of Henri Bergson. Particularly influential in this regard was his notion that time as delineated on the clock (temps) does not represent time as experienced in the individual psyche (durée); the former being quantitative, objective, and public, while the latter is qualitative, subjective, and private. An example from Bergson's Time and Free Will should illuminate the way in which he distinguishes these versions of time:

Whilst I am writing these lines, the hour strikes on a neighbouring clock, but my inattentive ear does not perceive it until several strokes have made themselves heard. Hence I have not counted them; and yet I only have to turn my attention backwards to count up the four strokes which have already sounded and add them to those which I hear. If, then, I question myself carefully on what has just taken place, I perceive that the first four sounds had struck my ear and even affected my consciousness, but that the 
sensations produced by each one of them, instead of being set side by side, had melted into one another in such a way as to give the whole a peculiar quality, to make a kind of musical phrase out of it. ... In a word, the number of strokes was perceived as a quality and not as a quantity. ${ }^{12}$

Bergson's distinctions between temps and durée, public and private, objective and subjective time remain prevalent in critical discussions about time and modernism. Nevertheless, not all modernists who dealt with time were directly influenced by Bergson (some were openly critical), and Bergson was not the only intellectual discussing time in the early years of the twentieth century.

Indeed, discussions about time were so common that Stephen Kern calls the years between 1880 and 1918 "the culture of time and space."13 One need not have read Bergson to be aware of his ideas, or the ideas of other theorists of time such as G.E. Moore, William James, and Bertrand Russell. Modern life alone led some people to generate questions about the nature of time; factors such as "technological changes, scientific theories, new conditions of work and daily life, [and] the increasing shift of populations to cities,"14 all contributed to an emerging sense that orderly, artificial timekeeping systems were, at best, inaccurate representations of time as the individual experienced it and, at worst, an impersonal force that steamrolled the individual into submission to modern ways of life. This threat is embodied in the linear organization of literary works. As a result, for writers hoping to depict the tension between clock and psychological time that people live with on a daily basis, the novel can only go so far. The radial orientation of images is more permissive of the individual's experience of time because images do not push readers/viewers to move in one direction (forward). 


\section{Images and Narrative Drive}

Thierry Groensteen argues that the individual panel in a comic "has the power to hail the reader, momentarily frustrating the 'passion to read' that drives the images so as always to be in the lead." 15 Indeed, panels interrupt the narrative drive into the future because the reader is momentarily halted, called upon to move his or her eyes up, down, left, or right; sometimes repeating the movement, sometimes reversing it, and often moving in directions that are the exact opposite of the left-to-right, top-to-bottom motion that signifies forward progress in Western novels.

To be sure, an artist might draw a panel in a way that directs the reader's gaze, causing most people to look first, say, at a road in an image by making this road large and in the center of the panel; by following the road, the reader's eye might then be drawn to animals on the side of the panel, and then to the trees just beyond the animals. But readers do not have to follow this set pattern when viewing a panel. A reader might notice the trees first and the road last. As A.A. Mendilow states, viewers of visual arts are "free to concentrate on any part of any size for any length of time and in any order, according to his own desire and not owning to any inherent necessity in the medium of sculpture or painting." ${ }^{16}$ Significantly, this idiosyncratic variation does not impede the viewer's ability to understand the portion of the narrative expressed within an individual panel of a comic. Certainly, readers of Western comics expect to move from topto-bottom and left-to-right on the page (though this pattern is often varied), but within each panel the reader is given latitude to move in alternate directions. Virginia Woolf, too, acknowledged the fact that "the formal railway line of sentence" runs counter to human consciousness: "people don't and never did feel or think or dream for a second in that way; but all over the place, in your own way. ${ }^{" 17}$ Radial orientation, by contrast, opens a space for reader autonomy, for individual 
experience, that is more akin to the psychological experience of time. Therefore, the presence of radially oriented panels within the broader linear structure of a comic as a whole amplifies the tension between psychological and clock time that so many modernists (Woolf included) strove to develop in their novels.

By virtue of this linear-radial orientation of comics, the reading experience is distinct from that of watching a film or seeing a painting. Movies, on the one hand, display images at a pre-determined narrative pace. Federico Fellini explains that "comics, more than film, benefits from the collaboration of the readers: one tells them a story that they tell to themselves; with their particular rhythm and imagination, in moving forward and backward." 18 In essence, the particular formal properties of comics allow, even require, the reader to experience the narrative at his/her own pace. Novels, of course, allow the same sort of individual pacing, but are still oriented linearly and so cannot achieve the same degree of tension between clock time and psychological time as comics. On the other hand, paintings are oriented radially but do not have the narrative drive which pushes readers constantly forward and thereby emulates clock time. Groensteen makes a similar point when he argues, "the comics image is not that of painting" due to the sequentiality of comics images; in other words, the position of panels within a larger system makes comics different from other art forms. ${ }^{19}$

Indeed, a narrative composed of text and images is an ideal way to create tension between clock time and the individual's psychological experience of it. Jacques Raverat seems to have anticipated this idea when, in a letter to Virginia Woolf, he argued that writing was “essentially linear"; Quentin Bell summarized his thoughts, stating that Raverat claimed the only way a writer could achieve the simultaneity enjoyed by painters would be through "some graphic expedient such as placing the word in the middle of a page and surrounding it radially with 
associated ideas. ${ }^{20}$ The combination of images and narrative sequence means that comics combine both the linear, clock-like orientation of novels and the radial orientation of images, with the panels repeatedly breaking up the flow of the narrative. The result is a reading experience that emulates the tension between clock time and psychological time.

Achieving this reading experience is due in no small part to a defining feature of comics: the gutter. Gutters divide panels into discrete units, each one thereby seeming to occupy a distinct moment in time. Scott McCloud has shown that time in comics is actually much more complicated - that it is more accurate to think of each panel as "occupying a time slot" 21 - but that readers nevertheless perceive the progression of panels to represent the progression of time, the unfolding of events in roughly chronological order. As McCloud says, "In learning to read comics we all learned to perceive time spatially, for in the world of comics, time and space are one and the same." 22 The first panel in a comic is understood to occur before the last one. Because of the gutter, each panel is distinct from the one before and after it, while also having a position in relationship to these other panels. Gutters function, then, to divide a narrative in a manner that is similar to the way a clock face divides hours and minutes into units that are whole onto themselves.

Although most comics have a fairly uniform system of gutters throughout a series, illustrators frequently play with gutters to achieve a narrative purpose. This is particularly true of pages and panels Benoit Peeters classifies as "rhetorical," or those in which "the panel and the page are no longer autonomous elements; they are subordinated to a narrative which their primary function is to serve. The size of the images, their distribution, the general pace of the page, all must come to support the narration. ${ }^{.23}$ Other types of panels balance narrative and artistic purposes. For instance, an illustrator might depict a particularly forceful punch by 
allowing the panel's action to spill over the border and into the gutter. This spillover is a visual manifestation of a character's pain and dizziness in the moment. If we read gutters as I am arguing, as divisions marking the passage of clock time, the disruption of the gutter in this example can be read as representing psychological time because it depicts an experience strong enough to knock the character out in two ways: to make him or her unconscious as well as out of sync with clock time. This simple device of breaking gutter borders is thereby a subtle, but effective, way to illustrate the tension between clock time and psychological time.

A more complex example occurs in League. In this case, illustrator Kevin O’Neill heightens the tension between clock and psychological time by not breaking gutter borders. League features a character known as the Prisoner of London, so named because he can time travel at will but cannot leave the geographical borders of London. ${ }^{24}$ The appearance of the Prisoner of London always occurs over a series of panels (generally between 3 and 4), each panel depicting London at different times. For example, in Century: 1969, the first panel in a series of three depicts London under attack by Martians (a reference to events in the first chapter of Century, set in 1910); this panel is followed by one set in the fictional world of George Orwell's 1984; the final panel is set in the present moment of the series, $1969 .{ }^{25}$ Although each panel expressly depicts a different time period, the Prisoner's presence in each panel is nearly identical: he stands in the same position, faces the same direction, in the same clothing.

The Prisoner's static presence in the panels heightens the continuity that already exists between panels, that is, the narrative drive that impels readers to develop chronological connections between panels. Nevertheless, each panel is oriented radially, which competes with the forward drive of the narrative. The reading experience is thus one of repeated shuttling between forward progression through the panels and idiosyncratic movement within each panel 
as readers attempt to understand the relationship between the Prisoner and the plot. In characteristically modernist fashion, Moore and O'Neill make readers work hard to understand the Prisoner's relationship to other characters and his role within the narrative because time does not operate in the manner we expect.

\section{Form and Content}

On a few occasions in League, characters seem to slip entirely out of clock time and exist in psychological time only (but only seem to, as I will later explain). One such occasion occurs toward the end of Century: 1969. Mina Murry, Allan Quatermain, and Orlando are fighting a supernatural villain named Oliver Haddo (based on a character created by W. Somerset Maugham). Mina encounters Haddo on a drug-fueled trip on the "astral plane." The importance of this climactic battle is mirrored in the panels of the book: a single image taking up $3 / 4$ of a twopage spread. This over-large panel is the culmination of a gutter breakdown that began several pages earlier. While most panels in this series have regular, 90-degree borders, in the pages leading up to the image depicting the battle, the borders grow increasingly wavy and objects begin breaking through them: first, a man steps just over the border and into the gutter, then a knife pierces the edge of a panel, and finally Haddo, in the figure of a green monster, obliterates the black line surrounding panels as his body becomes the border of the panel. This progressive gutter dissolution represents the decreasing hegemony of clock time for Mina while also showing the increasing effects of the hallucinogenic drug.

Panels demonstrating Mina's experience are occasionally interrupted by ones depicting action occurring to other, sober, characters. When this happens, the gutters between the panels become regular, 90-degree angles again. This change is, of course, intended to depict the 
difference between sober and drugged characters. Nevertheless, the gutter distortions do not function only on the level of content. The change also alters the reading experience. As divisions between panels break down, so too does the forward pull of the narrative for readers: the order in which we are supposed to read the panels becomes less directed, more open to individual choice until we encounter the large, 3/4-page panel that invites readers to experience their own psychological time alongside Mina.

Arguably, comics have the potential to be more successful than novels in depicting the tension between psychological and clock time by virtue of the genre's form. The following scene from Faulkner's As I Lay Dying (1930) will help elucidate the point:

“Where's Jewel?" pa says. When I was a boy I first learned how much better water tastes when it has set a while in a cedar bucket. Warmish-cool, with a faint taste like the hot July wind in cedar trees smells. It has to set at least six hours, and be drunk from a gourd. Water should never be drunk from metal. ${ }^{26}$ This interior monologue continues for nearly a full page. When Darl finally answers Anse's question - “'Down to the barn,' I say. 'Harnessing the team'”27 - readers are often caught by surprise because the focus of the narrative is anything but Jewel's location. Presumably only a few seconds elapse between Anse's question and Darl's response, but readers must take a minute or more to read the page of interior monologue. ${ }^{28}$ This discrepancy accounts for readers' surprise while also making them aware of the difference between Darl's psychological time and the clock time in which characters exist collectively.

As successful as Faulkner's method of depicting psychological time is, the genre he employs is still linear, which means the narrative retains the forward push of clock time even as Faulkner attempts to interrupt it with the more idiosyncratic experience of psychological time. In 
other words, readers can only get a limited experience of Darl's psychological time because we must continue to receive the narrative in an inexorably forward, linear movement. The content may toggle between psychological and clock time, but the form is always linear. In comics, both form and content may alternate between the two versions of time.

\section{Public and Private Time}

Returning to Mina's trip on the "astral plane," it is significant that her experience is not a pleasant one. In truth, it is a dangerous, harrowing event. Haddo comes close to destroying Mina's soul, and her body - which remains inert in the physical world - is sexually assaulted. This encounter with Haddo occurs because he is able to breach the boundary of her subjective experience and intrude on her psychological time. Although this breach is possible within the narrative because of the hallucinogenic drug Mina took, the events are suggestive for other circumstances. Indeed, this reading of Mina's psychological time raises questions about the extent to which psychological time is private, as it is usually understood to be.

Clock time regulates everyone in the same way: an hour lasts sixty minutes no matter who you are or what you are doing. Furthermore, clock time is generally a system agreed upon by a governing body to regulate its people and its business. These properties lead critics to refer to clock time as public. The private nature of psychological time would seem to be self-evident. Psychological time is, after all, the passage of time as perceived by an individual, based on his or her subjective experiences. These public and private versions of time are usually understood to be mutually exclusive. Paul Ricoeur, in his seminal study Time and Narrative, argues that public "monumental" time and private "mortal" time are "irreconcilable",; 29 there exists an 
"insurmountable fissure ... between the monumental time of the world and the mortal time of the soul. ${ }^{30}$

League's depiction of Haddo within Mina's psychological experience of time brings the private nature of psychological time into question. Indeed upon consideration, it becomes clear that psychological time is not private at all. For example, we often perceive the passage of time in the same way as others. Just think how often someone's complaint about time passing slowly in a meeting is met by groans of agreement from co-workers. Furthermore, when we experience time passing more slowly or more quickly than clock time, we still exist in and are subject to the public sphere. That is to say, our experience of psychological time is mediated by the concurrent actions of the people, events, and objects surrounding us; class drags by for a student because the professor is a boring lecturer, and it conversely speeds up when lectures are lively. Indeed, a field of psychology has recently emerged around this and similar sensations. Called embodied cognition, researchers in this field study the ways in which a person's subjective time is affected by the emotions of the people around him or her. ${ }^{31}$

Conversely, League suggests ways in which clock time has private, subjective aspects. To explain, consider the fact that the modernist sense of clock time as impersonal and potentially hazardous to individual psychology is markedly different from depictions of clock time in other eras. As Adam Barrows argues, Victorian literature usually depicts clock time as a tool to help people tame threats and points to Stoker's Dracula (1897) as an exemplary text. For example, Mina says that "the 'whole connected narrative' of Dracula is produced ... by 'knitting together in chronological order every scrap of evidence they have' and passing it among the hunters to be studied as "evidence." 32 The final product of this knitting, according to Barrows, "translates into a uniform typewritten font the individual idiosyncrasies of handwriting style or vocal pattern, a 
translation that . . 'excludes all particularities in favor of a general equivalence.",33

Homogenous clock time is central to the protagonists' ability to thwart Dracula.

Modernist texts, in contrast, are much more skeptical or even fearful of clock time.

Barrows explains this fear by placing clock time in historical context:

The period during which Greenwich Mean Time became accepted, nation by nation, as Universal Time, spans the period in English literary history typically associated with high modernism ... Greenwich, by the early twentieth century, had entered modernist consciousness as a powerful symbol of authoritarian control from a distance and of the management of diverse populations. ${ }^{34}$

This context helps explain why, in Woolf's Orlando, clock time is dangerous. Chimes marking the hour are "awful and ominous"; they strike "remorselessly," "violently assault" Orlando, and "hurtle through her like a meteor." 35 As Mark Hussey states, "Clock time threatens an individual's sense of continuity" because it takes no account of the lived experience of time."36 It is important to note that Woolf's Orlando positions clock time as an element external to Orlando. Clock time is a public force that threatens the individual.

By the twenty-first century, however, clock time appears to have lost much of its punch. We may feel hampered by clock time, but it hardly seems like a violent threat. In accordance, League transforms clock time into the character Orlando. Rather than the clock being an external entity - a machine whose sounds intrude upon Orlando's psychological time - Orlando's voice becomes the chimes of the clock. In this series, Orlando regularly refers to historical events experienced over the course of his/her very long lifetime. These references to events function as the chiming clock, reminders of the passage of time. 
For example, at the beginning of Century: 1969, Orlando remarks that Dover, where the group's ship landed, is not far from London: "We built a road straight there when I landed here with Caesar. Or was it Agricola? Actually, I led the Romans to London, having helped Brutus found the city when ..." Mina interrupts, stating, "Lando, shut up ... Although you're right about the road." ${ }^{\prime 37}$ Mina's reaction is typical. The other characters are generally indifferent to or annoyed by Orlando's rather arrogant reminders that he/she has lived longer than any of the others. Yet their annoyance also stems from the fact that Orlando is a wildly inaccurate clock. $\mathrm{He} / \mathrm{she}$ is often confused about where and when events happened. No one could stop Dracula by Orlando's memory of events, but neither is anyone haunted by clock time.

\section{Conclusion}

By personifying the clock, League encourages readers to see the ways in which it is private, subjective, and irregular. Even if clock time measures out history in regular intervals, humans nevertheless relate to it through our experiences; in other words, our relationship to clock time is always mediated by personal experience. The union of text and image in comics emulates the private/public character of clock time by asking readers to constantly shift between the linear pull of the narrative and the radial orientation of the panels. This linear-radial orientation of comics thereby carries on modernist experiments with time in powerful, if not always intentional, ways.

The legacy of modernism in the twenty-first century is sometimes easy to spot: novelists' persistent experiments with form, the unquestioned presence of free verse in poetry, or even the continued salience of Freudian concepts in Anglo-American literature. In other ways, the legacy of modernism is harder to find, particularly in the world of pop culture where many of the traits 
that traditionally characterize modernism - allusiveness, defamiliarization, alienation, and so forth - might seem to preclude the crowds and the money that are thought to be necessary for pop culture success. Yet as this essay has shown, paying attention to time in the hugely popular League series helps illuminate modernism as a red thread running all the way into the twentyfirst century, and surprisingly - but decisively - into the world of comics.

\section{Notes}

\section{Bibliography}

Auerbach, Erich. Mimesis: The Representation of Reality in Western Literature. Translated by Willard R. Trask. 1953. Reprint, Princeton, NJ: Princeton, 2003.

Banfield, Ann. “Time Passes: Virginia Woolf, Post-Impressionism, and Cambridge Time.” Poetics Today 24, no. 3 (2003): 471-516.

Barrows, Adam. “"The Shortcomings of Timetables': Greenwich, Modernism, and the Limits of Modernity.” MFS: Modern Fiction Studies 56, no.2 (2010): 262-89.

Bell, Quentin. Virginia Woolf: A Biography. New York: Harcourt Brace Jovanovich, 1972.

Bergson, Henri. Time and Free Will: An Essay on the Immediate Data of Consciousness. Translated by F.L. Pogson. 1889. Reprint, New York: Harper, 1960.

Carrier, David. The Aesthetics of Comics. University Park, PA: Pennsylvania State University Press, 2000.

Droit-Volet, Sylvie. "How Emotions Colour our Perception of Time." Trends in Cognitive Sciences 11, no. 12 (2007): 504-513. 
Faulkner, William. As I Lay Dying. 1930. Reprint, New York: Vintage, 1985. Requiem for a Nun. 1951. Reprint, New York: Vintage, 2011.

Frank, Joseph. "Spatial Form in Modern Literature: An Essay in Three Parts." The Sewanee Review 53, no. 4 (1945): 643-53.

Groensteen, Thierry. The System of Comics. Jackson, MS: University Press of Mississippi, 2007. Hussey, Mark, The Singing of the Real World: The Philosophy of Virginia Woolf's Fiction. Columbus, OH: Ohio State University Press, 1986.

Lessing, Gotthold Ephraim. Laocoon: An Essay on the Limits of Painting and Poetry. Translated by E.C. Beasley. London: Brown, Green, and Longmans, 1853.

Maugham, W. Somerset. The Magician. London: Heinemann, 1908.

Mendilow, A.A. Time and the Novel. New York: Humanities, 1972.

McCloud, Scott. Understanding Comics: The Invisible Art. New York: Harper Perennial, 1994.

Moore, Alan and Kevin O’Neill. Century: 1969. Marietta, GA: Top Shelf, 2011.

O’Sullivan, James. "Time and Technology in Orlando.” ANQ: A Quarterly Journal of Short Articles, Notes, and Reviews 27, no.1 (2014): 40-5.

Peeters, Benoit. "Four Conceptions of the Page." Translated by Jesse Cohn. ImageTexT: Interdisciplinary Comics Studies 3, no.3 (2007): 41-60.

Ricoeur, Paul. Time and Narrative, vol. 2. Translated by Kathleen McLaughlin and David Pellauer. Chicago: University of Chicago Press, 1985.

Shklovsky, Viktor. “Art as Technique.” Literary Theory: An Anthology, edited by Julie Rivkin and Michael Ryan. Malden, MA: Blackwell, 2004.

Sinclair, Iain, and David McKean, Slow Chocolate Autopsy: Incidents from the Notorious Career of Norton, Prisoner of London. London: Phoenix House, 1997. 
Stevenson, Randall. Modernist Fiction. Lexington, KY: University Press of Kentucky, 1992.

Stoker, Bram, Dracula. 1897. Reprint, London: Vintage, 2013.

Woolf, Virginia, Orlando: A Biography. Edited by Marie DiBattista. 1928. Reprint, Orlando, FL: Harcourt, 2006.

—. To the Lighthouse. 1927. Reprint, New York: Harcourt Brace Jovanovich, 1981.

${ }^{1}$ Ann Banfield makes this argument via Jacques Raverat and Roger Fry. Others have noted the linear, time-based organization of writing, among them Gotthold Ephraim Lessing, Joseph Frank and A.A. Mendilow. Ann Banfield, "Time Passes: Virginia Woolf, Post-Impressionism, and Cambridge Time," Poetics Today 24,, no. 3 (2003): 472-3.

${ }^{2}$ Ibid.

${ }^{3}$ Scott McCloud, Understanding Comics: The Invisible Art (New York: Harper Perennial, 1994), 18.

${ }^{4}$ Eric Berlatsky, "Time and Free Will: Bergson, Modernism, Superheroes, and Watchmen," in Understanding Bergson, Understanding Modernism, ed. Paul Ardoin, S.E. Gontarski, and Laci Mattison (New York: Bloomsbury, 2013), 262.

${ }^{5}$ Quoted in A.A. Mendilow, Time and the Novel (New York: Humanities, 1972), 16.

${ }^{6}$ Alan Moore and Kevin O’Neill, Century: 1969 (Marietta, GA: Top Shelf, 2011), n.p.

${ }^{7}$ William Faulkner, Requiem for a Nun (1951; repr., New York: Vintage, 2011), 73.

${ }^{8}$ Randall Stevenson, Modernist Fiction (Lexington, KY: University Press of Kentucky, 1992), 87.

${ }^{9}$ Banfield, "Time Passes,” 473. 
${ }^{10}$ Erich Auerbach, Mimesis: The Representation of Reality in Western Literature, trans. Willard R. Trask (Princeton, NJ: Princeton, 2003), 537.

${ }^{11}$ Viktor Shklovsky, “Art as Technique," in Literary Theory: An Anthology, ed. Julie Rivkin and Michael Ryan (Malden, MA: Blackwell, 2004), 18.

${ }^{12}$ Henri Bergson, Time and Free Will: An Essay on the Immediate Data of Consciousness, trans. F.L. Pogson (1889; repr., New York: Harper, 1960), 127-8.

${ }^{13}$ I am indebted to Banfield for this observation. Banfield, "Time Passes," 473.

${ }^{14}$ Ibid.

${ }^{15}$ Thierry Groensteen, The System of Comics (Jackson, MS: University Press of Mississippi, 2007), 26.

${ }^{16}$ Mendilow, Time and the Novel, 25.

${ }^{17}$ Quoted in Quentin Bell, Virginia Woolf: A Biography (New York: Harcourt, 1972), 338.

${ }^{18}$ Quoted in Groensteen, System, 11.

${ }^{19}$ Ibid., 7. Groensteen nevertheless argues that comics should be thought of as a primarily visual art form. He states that scholars of comics must "renounce" the idea that "comics are essentially a mixture of text and images, a specific combination of linguistic and visual codes" (3). I incline to David Carrier's argument, which positions comics as a composite art form, a combination of text and language, on the basis of the speech balloon as a defining characteristic. For more, see Carrier, The Aesthetics of Comics (University Park, PA:

Pennsylvania State University Press, 2000), 4.

${ }^{20}$ Bell, Virginia Woolf, 338.

${ }^{21}$ McCloud, Understanding Comics, 97.

${ }^{22}$ Ibid, 100. 
${ }^{23}$ Benoit Peeters, "Four Conceptions of the Page," trans. Jesse Cohn, ImageTexT: Interdisciplinary Comics Studies 3, no. 3 (2007): par. 19.

${ }^{24}$ The Prisoner of London is based on a character from Iain Sinclair and David McKean's Slow Chocolate Autopsy.

${ }^{25}$ Moore, Century: 1969, n.p.

${ }^{26}$ William Faulkner, As I Lay Dying (1930; repr., New York: Vintage, 1985): 10-11.

${ }^{27}$ Ibid., 11.

${ }^{28}$ My reading of the scene is influenced by Auerbach's reading of To the Lighthouse in Mimesis.

${ }^{29}$ Paul Ricouer, Time and Narrative, vol. 2, trans. Kathleen McLaughlin and David Pellauer (Chicago: University of Chicago Press, 1985): 107.

${ }^{30}$ Ibid., 110.

${ }^{31}$ See, for example, Sylvie Droit-Volet, "How Emotions Colour our Perception of Time," Trends in Cognitive Sciences 11, no. 12 (2007).

${ }^{32}$ Quoted in Adam Barrows, “'The Shortcomings of Timetables': Greenwich, Modernism, and the Limits of Modernity," MFS: Modern Fiction Studies 56, no. 2 (2010): 283.

${ }^{33}$ Ibid.

${ }^{34}$ Barrows, "Shortcomings," 263.

${ }^{35}$ Virginia Woolf, Orlando: A Biography, ed. Marie DiBattista (1928; repr., Orlando, FL: Harcourt, 2006): 45; 224; 236.

${ }^{36}$ Mark Hussey, The Singing of the Real World: The Philosophy of Virginia Woolf's Fiction (Columbus, OH: Ohio State University Press, 1986), 122.

${ }^{37}$ Moore, Century: 1969, n.p. 